\title{
Development of a LRT simulator for demand forecasting
}

\author{
N. Kudo \& T. Mizuma \\ National Traffic Safety and Environment Laboratory, Japan
}

\begin{abstract}
We developed the LRT introduction effect simulator. The increase in the number of heat-trapping gases such as carbon dioxide is a global problem. Decreasing this number is essential. The thought is that a modal shift from the car to public transportation is effective in the traffic field. However, when public transportation is introduced, a quantitative effect is needed in Japan. We have developed a simulator, whereby the selection of car, railway or bus, which has not been included in past simulators, is used to calculate the running energy of transportation. The simulator then reports the selection of the individual's means, with the model being built using the Analytic Hierarchy Process.
\end{abstract}

Keywords: simulation, LRT, demand forecast.

\section{Introduction}

As a global problem, the amount of greenhouse effect gases such as carbon dioxide is increasing. The task of pressing urgency is to reduce greenhouse effect gases. Each industrial field is trying to reduce greenhouse effect gases. It is supposed that a modal shift from automobiles to public transportation would be effective in the traffic field.

Meanwhile, presentation of quantitative effect is often required when introducing public transportation in Japan. For that purpose, we have developed a simulator, however, we have not considered the human mentality. Therefore, we incorporated selection by people, making the means model in the simulator by using AHP (Analytic Hierarchy Process). 


\section{Background of research}

\subsection{Environmental problems}

A worldwide problem is increasing greenhouse effect gases such as carbon dioxides. Greenhouse gas reduction is a task of pressing urgency. Figure 1 shows $\mathrm{CO}_{2}$ emissions in Japan in 2006. Figure 2 shows $\mathrm{CO}_{2}$ emissions for transportation. The figure shows automobiles account for a large portion of $\mathrm{CO}_{2}$ emissions. The automotive industry continues efforts such as the improvement of fuel efficiency and the introduction of hybrid cars as well as electric toll

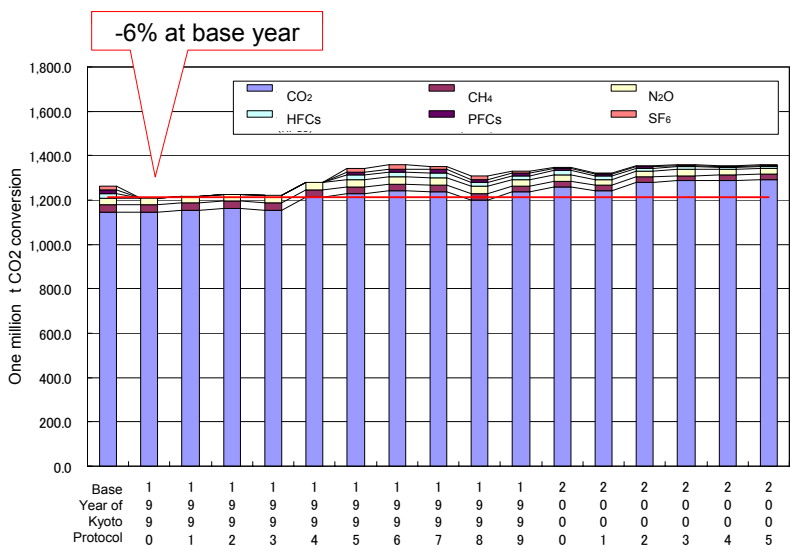

Source: Japanese country heat-trapping gas inventory report (NIR) Version, heat-trapping gas inventory office, May 2007

Figure 1: $\quad$ Amount of $\mathrm{CO}_{2}$ exhaust.

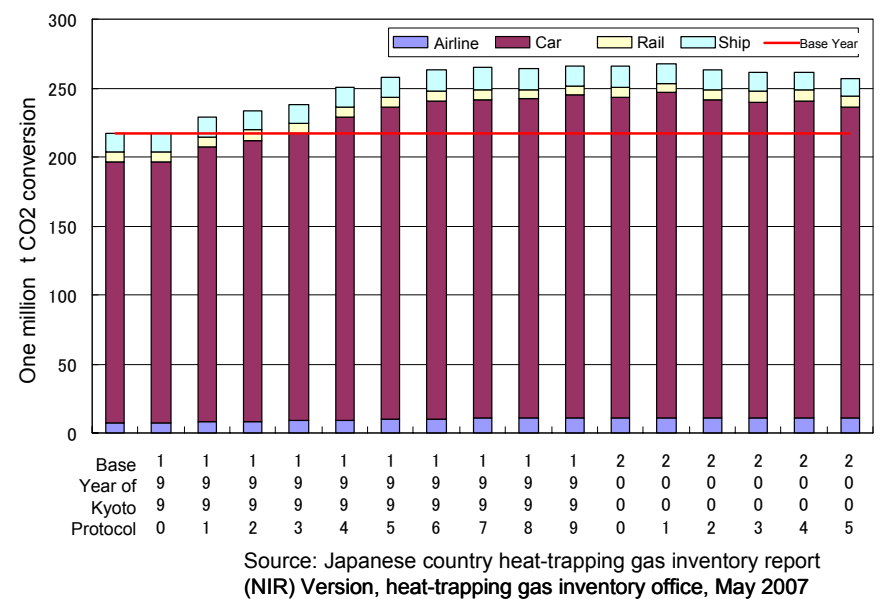

Figure 2: $\quad$ Amount of $\mathrm{CO}_{2}$ exhaust in the traffic field. 
collection (ETC). However, the effect is insufficient at this moment. Therefore, it is supposed that a modal shift from automobiles to public transportation would be effective.

\subsection{Current state of the tram network}

The tram network was constructed in the 1920s, and it functioned as important transportation for cities in Japan.

However, it was pushed out by motorization when the ownership rate of the car increased in the $1960 \mathrm{~s}$, it was assumed that the tram was a ringleader of congestion, and was abolished in various places at the end of the 1970s.

However, when environmental problems in recent years are considered, a modal shift to public transport, especially LRT (Light Rail Transit), is considered effective. On the other hand, at the current time it will be a difficult introduction since the tram was previously abolished and it could be considered to have a negative influence on already saturated road traffic.

\section{Our traffic flow simulator}

\subsection{Current version}

\subsubsection{Simulator characteristics}

The outline of the simulator we are developing is shown in Table 1. We extract the automobile, bus and public transport of LRV as the transportation system. These vehicles are running with their performance monitored so that we can design in accordance with their timetables and the O/D (Origin and Destination) table, which we can set beforehand.

Table 1: $\quad$ Outline of simulator.

\begin{tabular}{|l|l|l|}
\hline \multirow{4}{*}{$\begin{array}{l}\text { Transportation } \\
\text { Systems }\end{array}$} & Function & Parameter \\
\cline { 2 - 3 } & BRV & $\begin{array}{l}\text { Route, performance, } \\
\text { timetable }\end{array}$ \\
\cline { 2 - 3 } Road & Automobile & $\begin{array}{l}\text { Route, performance, } \\
\text { timetable }\end{array}$ \\
\hline LRT measure & $\begin{array}{l}\text { Network according } \\
\text { to road map }\end{array}$ & $\begin{array}{l}\text { Performance, O/D } \\
\text { Line, Running } \\
\text { Direction }\end{array}$ \\
\cline { 2 - 3 } Signal & Pransit mall & Area \\
\hline & $\begin{array}{l}\text { Each transport runs according } \\
\text { to signal }\end{array}$ & $\begin{array}{l}\text { Parking space } \\
\text { Lycle time, } \\
\text { LRV priori signal }\end{array}$ \\
\hline
\end{tabular}

\subsubsection{Output of simulation results}

This simulator can calculate and show the following results.

(a) running numbers of each method of transportation over the simulation time,

(b) maximum and minimum running time between the appointed crossings, 
(c) average speed of each method of transportation over the simulation time,

(d) the running energy of each type of transportation between the appointed crossings,

(e) the amount of exhausted $\mathrm{CO}_{2}$ and $\mathrm{NO}_{\mathrm{X}}$ over the simulation time.

All calculated data are shown on the simulator's monitor as the simulation is running.

\subsection{Routing model}

The physical quantity of traffic moving in a certain area could be calculated and any number of vehicles could be set by the conventional simulator. Therefore, the effect of introducing transportation means could be readily calculated by inputting values although it was highly likely that the effect did not reflect the realities. Consequently, we decided to incorporate a model using the AHP to reduce the variations in the process of calculating the effect of introducing transportation means through a routing model.

\subsubsection{What is the AHP? [1]}

The AHP is a decision-making tool in uncertain conditions or various evaluation criteria. In the AHP, problematic factors are understood in the relationship between the final target, the evaluation criteria and alternatives to establish a hierarchical structure. Then, the importance of evaluation criteria from the viewpoint of the final target is obtained. Next, each alternative is evaluated based on each evaluation criteria. Finally, the alternatives are converted into the evaluation of each alternative observed from the final target. The AHP method has a feature of being able to manage items that were hardly modelled or quantified in the process of evaluation.

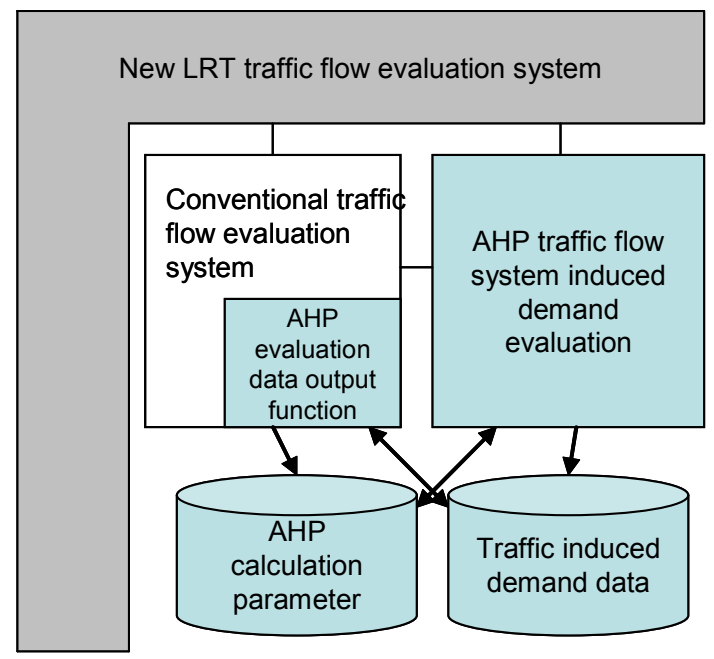

Figure 3: $\quad$ Composition of traffic flow simulator. 


\subsubsection{Evaluation of urban transportation systems and the AHP method}

We developed a model that enables evaluation of analytical methods to which the AHP is applied in order to evaluate the current and future urban transportation system. Figure 3 shows the relationship between the conventional system and added functions.

The routing model shows how inhabitants in each town block of a simulated area change their choices when the transportation system is changed. This simulator converts the AHP parameters into numerical values through stage assessment when a traffic simulation starts and uses the values as the initial value of a traffic flow simulation. As a result, approximate travel time, access time, energy consumption, $\mathrm{CO}_{2}$ emission, and other details are obtained from the traffic flow simulation. They are again input to the AHP evaluation to be reevaluated. A traffic simulation is also performed again based on the results. This procedure is repeated until convergence is obtained.

As shown in Figure 4, evaluation items from the viewpoint of transportation enterprises, users and sociality are input to the hierarchic structure in order to evaluate a traffic system. Then, importance is compared among evaluation criterion elements and target systems. Finally, priority of applicability is decided.

Table 2 shows the information that the AHP receives from the traffic flow simulation.

\section{Simulation}

We did a trial calculation as an introduction example in a town. This town has a streetcar, however, many people use automobiles.

\subsection{Simulation area}

Figure 5 shows the target area. Streetcars and a railroad run in the town. In the simulation, we defined an area from the railway station to the northern station so that people could demand transportation in the area. Additionally, buses run in the town. We used only bus routes related to the demand as the definition simulation target.

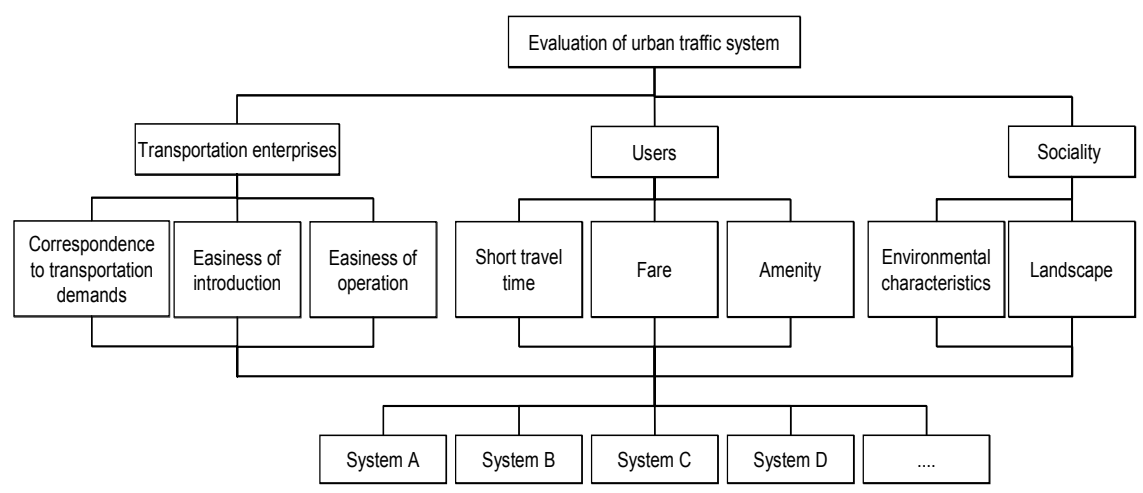

Figure 4: Hierarchic structure. 
Table 2: $\quad$ AHP parameter from the traffic flow simulator.

\begin{tabular}{|c|c|c|c|c|c|}
\hline No & Viewpoint & Medium item & Minor items & $\begin{array}{l}\text { Output } \\
\text { information }\end{array}$ & Notes \\
\hline 1 & \multirow[t]{2}{*}{$\begin{array}{l}\text { Transportation } \\
\text { enterprises }\end{array}$} & $\begin{array}{l}\text { Ease of } \\
\text { introduction }\end{array}$ & $\begin{array}{l}\text { Energy } \\
\text { Consumption }\end{array}$ & $\begin{array}{l}\text { Fuel and } \\
\text { electricity } \\
\text { consumption of } \\
\text { each } \\
\text { transportation } \\
\text { system }\end{array}$ & $\begin{array}{l}\text { Crude oil } \\
\text { equivalent } \\
\text { should be } \\
\text { used to unify } \\
\text { evaluations. }\end{array}$ \\
\hline 2 & & $\begin{array}{l}\text { Correspondence } \\
\text { to transportation } \\
\text { demands }\end{array}$ & $\begin{array}{l}\text { Transportation } \\
\text { capability }\end{array}$ & $\begin{array}{l}\text { Total number of } \\
\text { persons who } \\
\text { used cars, } \\
\text { buses, LRTs, } \\
\text { streetcars, etc. } \\
\text { should be } \\
\text { output for each } \\
\text { transportation } \\
\text { system. }\end{array}$ & $\begin{array}{l}\text { Car: } 1.2 \\
\text { persons per } \\
\text { car } \\
\text { Bus: } \\
\text { Number of } \\
\text { users } \\
\text { LRT: } \\
\text { Number of } \\
\text { users }\end{array}$ \\
\hline 3 & \multirow[t]{3}{*}{ Users } & Access & $\begin{array}{l}\text { Time required } \\
\text { from/to a station } \\
\text { and a bus stop }\end{array}$ & $\begin{array}{l}\text { Inverse } \\
\text { normalization }\end{array}$ & Access \\
\hline 4 & & \multirow{2}{*}{\begin{tabular}{|l} 
Frequency \\
Schedule speed
\end{tabular}} & $\begin{array}{l}\text { Outputs number } \\
\text { of operating } \\
\text { vehicles per } \\
\text { hour }\end{array}$ & $\begin{array}{l}\text { No simulation } \\
\text { is required. }\end{array}$ & Frequency \\
\hline 5 & & & $\begin{array}{l}\text { Average speed } \\
\text { of target } \\
\text { vehicles }\end{array}$ & $\begin{array}{l}\text { Calculate the } \\
\text { average speed } \\
\text { from door to } \\
\text { door (including } \\
\text { walking time). }\end{array}$ & $\begin{array}{l}\text { Schedule } \\
\text { speed }\end{array}$ \\
\hline 6 & Sociality & $\mathrm{CO}_{2}$ & $\begin{array}{l}\mathrm{CO}_{2} \text { emission } \\
\text { (including } \\
\text { period of } \\
\text { electric } \\
\text { generation and } \\
\text { gasoline } \\
\text { purification) }\end{array}$ & $\begin{array}{l}\text { Inverse number } \\
\text { normalization }\end{array}$ & $\mathrm{CO}_{2}$ \\
\hline
\end{tabular}

We also performed traffic censuses at three points and reproduced the traffic flow based on the results. These data include traffic volume, the number of pedestrians and bicycles that cross at the crosswalks of each intersection and signal phases.

\subsection{Calculation of route selected by AHP}

With the AHP, we calculated the simulation area shown above. At first, we calculated the current route choice. Figure 6 shows the calculated results. Figure 7 shows the calculation results assuming LRT is used and the number of trains in service is doubled. It was confirmed that calculations converged during the third and fourth time, respectively. 


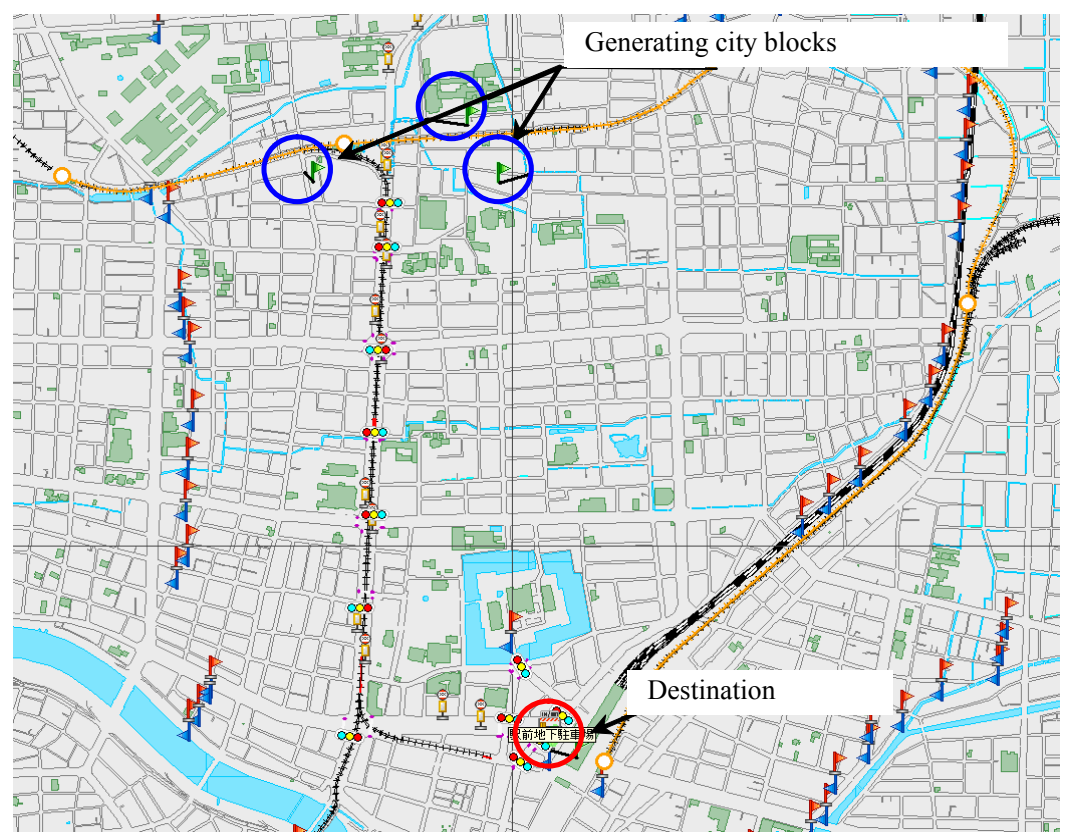

Figure 5: $\quad$ Range of the case study.

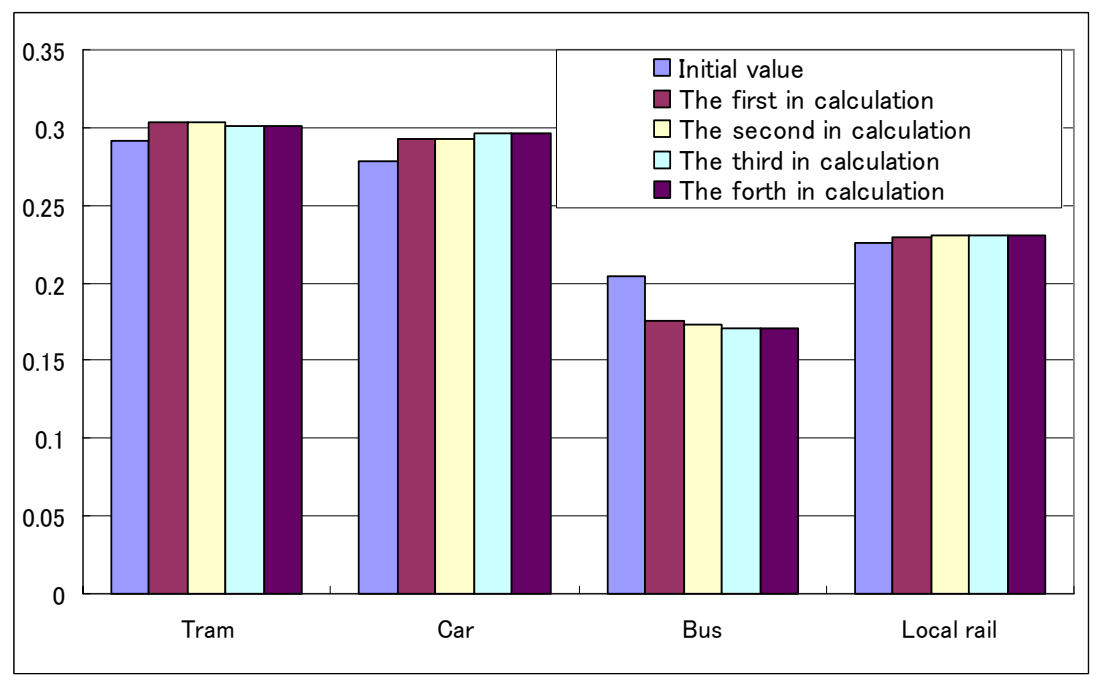

Figure 6: Route choice ratio (current situation). 


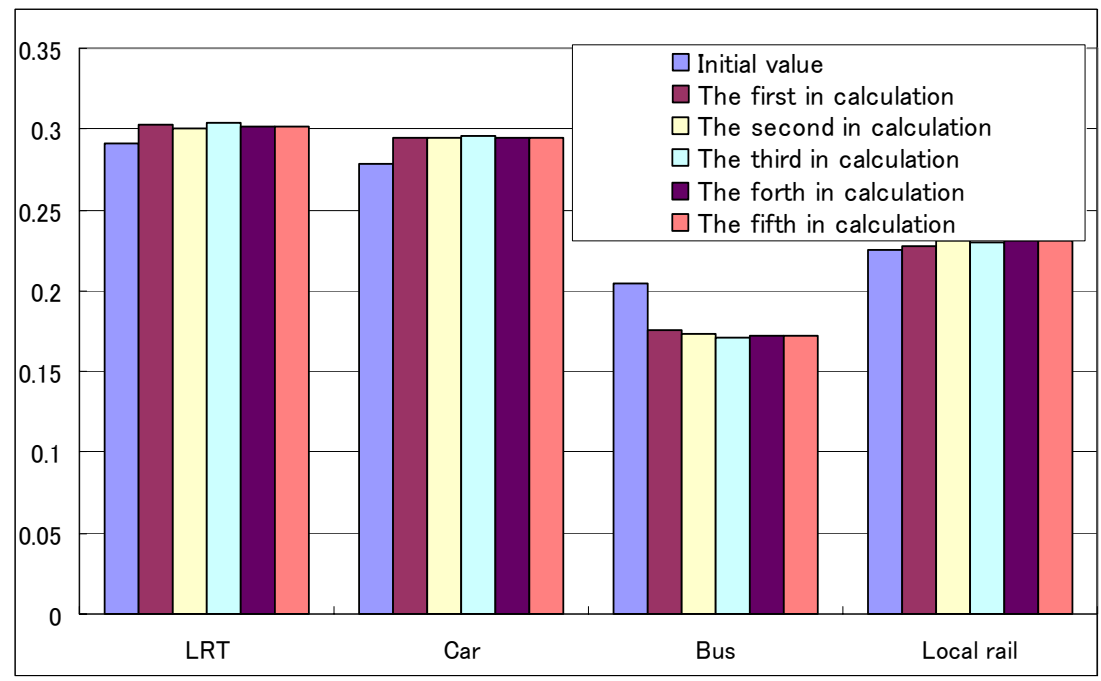

Figure 7: $\quad$ Route choice ratio (LRT is used).

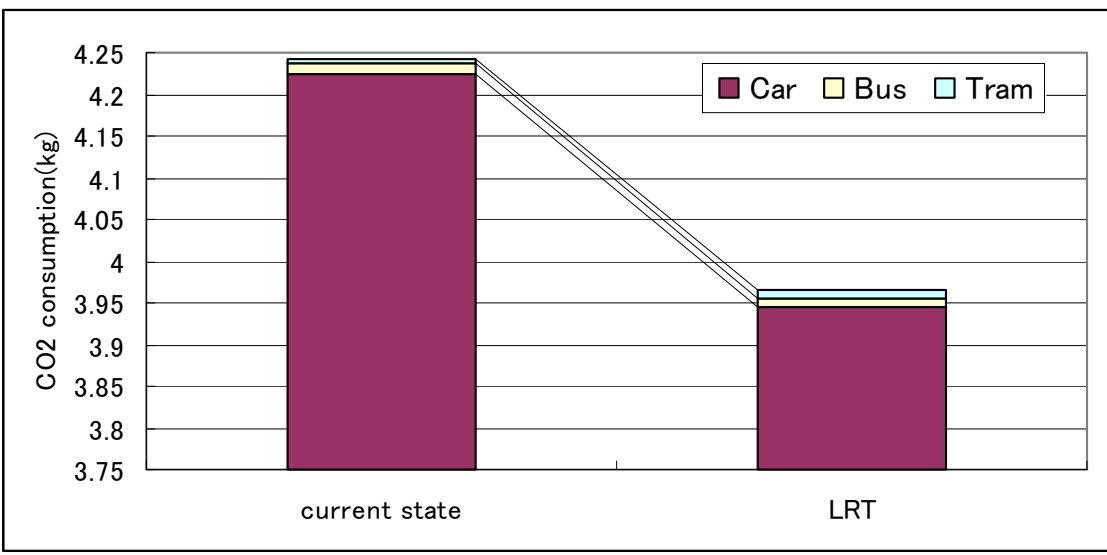

Figure 8: $\quad \mathrm{CO}_{2}$ emission.

Additionally, LRT and automobiles had comparable demand at those generating points. Demands for the local rail, which went by a significantly roundabout route, and for buses, which had fewer buses in service, were small. A comparison of Figures 6 and 7 shows that only the shift to LRT and an increased number of trains in service did not make people shift from automobiles to the LRT.

Figure 8 is a graph of $\mathrm{CO}_{2}$ emission when a one-hour simulation was carried out before and after using LRT. Figure 8 estimates that approximately $200 \mathrm{~kg}$ of $\mathrm{CO}_{2}$ can be eliminated in the simulated area because the choice of transportation means was changed. 


\section{Conclusion}

We developed traffic flow simulators as tools for quantitatively indicating the effect of introducing public transportation. In this study, we incorporated a route choice model using the AHP to resolve the problem that the generating point number could be decided in an arbitrary manner. The AHP confirmed that routing choice could be calculated. Additionally, we could demonstrate that the route choice model was reflected in the quantitative calculation of the traffic flow simulator. We will simultaneously choose routes from more generating points to calculate the effect of introducing the LRT in further research.

\section{Reference}

[1] Kinoshita E. AHP Method and Applications, Sougou-Gijutsu-Center (1993) 